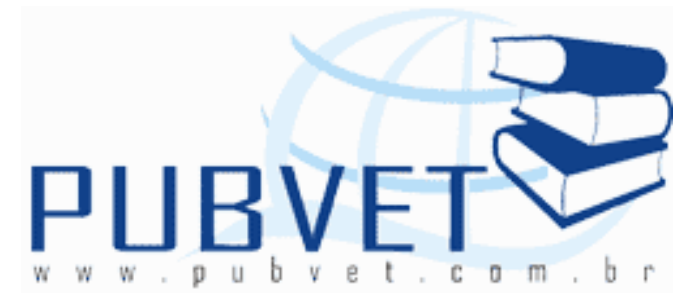

PUBVET, Publicações em Medicina Veterinária e Zootecnia.

\title{
Soroepidemiologia da Brucelose em equinos de trabalho de áreas rurais do Município de Uberlândia-MG
}

\footnotetext{
André Luiz Quagliatto Santos ${ }^{1}$, Anna Monteiro Correia Lima-Ribeiro ${ }^{1}$, Sérgio Rodrigo Pereira de Oliveira ${ }^{2}$, Árthur Paulino Sanzo Kaminishi ${ }^{2}$, Mariana Batista Andrade $^{3}$, Lorena Tannús Menezes ${ }^{2}$, Rogério Rodrigues de Souza ${ }^{2}$, Caio Henrique Ferreira ${ }^{2}$, Liliane Rangel Nascimento ${ }^{2}$, Flávio Machado de Moraes ${ }^{1}$
}

Laboratório de Ensino e Pesquisa em Animais Silvestres - LAPAS, FAMEV/UFU, e-mail: quagliatto@famev.ufu.br 1. Docente. 2. Mestrandos. 3. Doutoranda.

\section{Resumo}

A Brucelose é uma doença infecto-contagiosa provocada por bactérias do gênero Brucella, de distribuição mundial, infecta diversas espécies de animais domésticos e até mesmo os humanos. Dentre as espécies animais em que a doença já foi diagnosticada incluem bovinos, caprinos, suínos, cães, ovinos, eqüinos, bubalinos e ratos do deserto. Poucos trabalhos na literatura abordam a doença na espécie eqüina, dificultando valores sobre a distribuição da doença a nível nacional e mundial. O presente trabalho teve como objetivo avaliar a prevalência da doença em eqüinos que prestavam serviço de tração em áreas rurais do município de Uberlândia-MG e esclarecer os mecanismos epidemiológicos envolvidos na cadeia de transmissão na região. Foram utilizados testes sorológicos, e, um questionário sócio-epidemiológico foi respondido por cada proprietário dos animais amostrados após a coleta do 
sangue. Foram avaliadas pelo teste do Antígeno Acidificado Tamponado (AAT), amostras sanguíneas de 187 animais, das quais 100\% apresentaram-se negativas ao teste. As condições de manejo, o sistema de monta, alojamento, alimentação e o isolamento de espécies de interesse sanitário na transmissão da brucelose aos eqüinos de tração contribuíram decisivamente como fatores limitantes para a disseminação desta doença a estes animais. Pode-se concluir que a brucelose é de baixa importância epidemiológica para eqüinos de trabalho em áreas rurais do município de Uberlândia - MG, sendo portanto stas áreas, um ecossistema livre da doença.

Palavras-chave: Brucelose eqüina, sorodiagnóstico, Antígeno Acidificado Tamponado, 2-Mercaptoetanol.

\title{
Soroepidemiology of brucellosis in working horses from rural areas of Uberlândia - MG
}

\begin{abstract}
The brucellosis is an infectious-contagious disease caused by bacterias of the Brucella gender, of general distribution, infects many species of domestic animals and even mankind. Among animal species in which the disease was already diagnosed are included bovine, goats, swine, dogs, ovine, equine, buffalo, and desert rats. Few works in the literature approach the disease in the equine species, bringing difficulties in the evaluation of the disease's distribution in a national and worldwide level. The present work was focused on evaluating the predominance of the disease in equines that worked as traction animals in the rural areas of the city of Uberlândia - MG and clarify the epidemiologic mechanisms evolved in the regional transmission chain. Serologic tests and a socio-epidemiologic questionary. In order to do that, serologic tests were used and a social-epidemiologic set of questions was answered by each owner after the blood sample collection. One hundred and eighty seven blood samples were evaluated by test of rose Bengal antigen (AAT), $100 \%$ of them being negative to the test. The handling conditions,
\end{abstract}


mounting system, storing, alimentation and isolation of the species of sanitary interest in the transmission of Brucellosis to the traction equines, had a decisive contribution as limiting factors to the dissemination of this disease to these animals. In conclusion, the equine brucellosis, doesn't have much epidemiologic importance for working equines in the rural sites of Uberlândia MG, which is an area rid of the given disease.

Keywords: Equine brucellosis, serodiagnóstic, test of rose Bengal antigen, 2Mercaptoethanol.

\section{INTRODUÇÃO}

A Brucelose é uma doença infecto-contagiosa provocada por bactérias do gênero Brucella, de distribuição mundial, infecta diversas espécies de animais domésticos e até mesmo os humanos. Dentre as espécies animais em que a doença já foi diagnosticada incluem-se bovinos, caprinos, suínos, cães, ovinos, eqüinos, bubalinos e ratos do deserto (KOLODA, 2005).

Animais infectados eliminam a bactéria em secreções vaginais, anexos fetais, fezes, leite, urina e sêmen. Assim outros animais se infectam ao ingerir água e alimentos contaminados com esses materiais, sendo as portas de entrada para a bactéria as mucosas orofaríngeas, conjuntivas, respiratórias, genitais, assim como pele com soluções de continuidade (DAVIS, 1972).

A doença é transmitida para seres humanos a partir de animais contaminados via consumo de leite cru ou derivados não pasteurizados, por exposição de fazendeiros, trabalhadores de laticínios e matadouros, médicos veterinários que manipulam ou que possam ter contato com os microorganismos (NICOLETTI, 2001).

Por ser uma zoonose e estar associada a certos grupos ocupacionais e ingestão de alimentos contaminados pela Brucella, a brucelose apresenta importante significado na saúde coletiva, particularmente, nos países em desenvolvimento, onde a doença em humanos ainda ocorre em função da doença animal (YOUNG, 1995). 
Em animais os principais prejuízos causados pela doença se referem aos abortos, infertilidades, repetições de cio, nascimento de filhotes fracos, diminuição na produção de leite, redução do tempo de vida produtiva do animal, custos para reposição de animais, limitações para comercialização de animais assim como carnes, leite e seus subprodutos e custos com tratamentos e programas de prevenção (RADOSTITS et al., 2000).

Eqüinos são elementos importantes na cadeia de perpetuação da brucelose devido ao íntimo contato desses animais com diversas espécies e, sobretudo o homem. Desse modo é importante reconhecer animais positivos e orientar pessoas que possuam contato com esses animais sobre riscos de infecção (ACHA; SZYFRES, 2001).

A brucelose em eqüinos merece preocupação em virtude das lesões debilitantes, pela indicação de Eutanásia dos animais acometidos, ou como fonte de infecção para outras espécies domésticas e, até mesmo para os humanos (RADOSTITS et al., 2000).

No Brasil, são escassos os estudos conduzidos na investigação da brucelose eqüina, o que limita delinear claramente a situação da enfermidade no país.

Este trabalho se justifica pela necessidade de se conhecer a prevalência de eqüinos infectados por brucelose, que transitam nas propriedades rurais da cidade de Uberlândia-MG, e no esclarecimento dos mecanismos de perpetuação da enfermidade nesta espécie neste ecossistema. $O$ fato dos eqüinos serem portadores do agente, e o seu contato com outras espécies animais e o homem, sugerem o impacto da doença nesta espécie sobre a saúde pública, uma vez que a brucelose é uma zoonose amplamente difundida no mundo.

Existem poucos trabalhos sobre esta importante doença em eqüinos da região. Embora tenha sido lançado em setembro de 2005 o Plano Nacional de Controle e Erradicação da Brucelose e Tuberculose (PNCEBT) com o objetivo de controlar a brucelose e a tuberculose bovina, o programa ainda não se estendeu ao controle da brucelose eqüina, o que torna de fundamental 
importância conhecer-se as características epidemiológicas e freqüência desta doença em eqüinos da região.

Os objetivos deste trabalho foram de identificar eqüinos portadores de brucelose nas áreas rurais de Uberlândia-MG, além de se determinar a prevalência dessa doença pelo método do AAT (Teste do Antígeno Acidificado Tamponado). Além disso, levantar dados que esclarecessem sobre a epidemiologia da doença, associando eventuais casos positivos, ao sexo, idade, raça e evidências clínicas, e orientação aos proprietários rurais onde eventualmente foram identificados casos de animais sororeagentes.

\section{METODOLOGIA}

Para a realização deste trabalho foram utilizadas amostras de sangue de 187 eqüinos de trabalho de áreas rurais, provenientes de Uberlândia - MG. O sangue foi colhido assepticamente pelo sistema Vacutainer, em tubos sem anticoagulantes, numa quantidade de $5 \mathrm{ml}$, e transportado para o Laboratório de Doenças Infecto-contagiosas da Universidade Federal de Uberlândia - UFU. Após a coagulação, este sangue foi centrifugado a 2.500 rotações por minuto, durante 10 minutos, para a obtenção dos soros.

A análise das amostras foi realizada através do Teste do Antígeno Acidificado Tamponado (AAT); o antígeno utilizado foi aquele de maior prevalência entre os eqüinos: Brucella abortus. Caso algum animal fosse positivo nesse teste, seria realizado o Teste do 2-Mercaptoetanol (2-ME) como confirmatório, e, caso ainda se apresentasse positivo, seria enviado aos laboratórios do Instituto Biológico em São Paulo, para ser analisado pelo teste de Fixação de Complemento com antígeno de Brucella abortus.

A forma de efetivar o teste AAT FOI descrito a seguir, baseada em recomendações do MAPA (2005). 
Teste AAT: o soro sanguíneo e as amostras de antígenos foram equilibrados à temperatura ambiente por, pelo menos 30 minutos, e em seguida o soro foi homogeneizado.

Foi depositada sobre placa de vidro $30 \mu \mathrm{L}$ de soro e, na mesma placa, do lado do soro depositou-se a mesma quantidade de antígeno $(30 \mu \mathrm{L})$. Esta amostra de soro-antígeno foi misturada com o uso de um misturador simples, em movimentos circulares, de modo a obter um círculo aproximado de $2 \mathrm{~cm}$. Após isso, a placa foi agitada com movimentos oscilatórios, em uma freqüência de 30 movimentos por minuto durante 4 minutos de modo a mistura soroantígeno fluir lentamente dentro de cada círculo.

A leitura das placas foi realizada com o uso da caixa de leitura com luz indireta. Considerou-se reagente o soro no qual formou uma reação de aglutinação em até 4 minutos, com a presença de grumos.

Número amostral: para calcular o tamanho da amostra tomou-se como valor de referência a porcentagem de soros positivos encontrados por Dias (2000), onde constatou-se $34,74 \%$ de animais positivos à Brucelose em fazendas da Ilha de Marajó.

O cálculo do número de eqüinos testados foi feito segundo recomendação do Centro Panamericano de Zoonoses - CEPANZO (1979), aplicando-se a seguinte fórmula:

$$
\mathrm{n}=\frac{\mathrm{p}(100-\mathrm{p}) \mathrm{a}^{2}}{\left(\frac{\mathrm{d} \cdot \mathrm{p}}{100}\right)^{2}}
$$

Onde:

$\mathrm{n}=$ tamanho da amostra

$p=$ prevalência esperada $(34,74 \%)$

$a=$ fator de confiança do grau de confiança $(1,96)$

$d=$ erro amostral (20\%)

Sendo: 
$\mathrm{n}=34,74(100-34,74) 4 /(20 \times 34,74 / 100)^{2}$

$\mathrm{n}=9068,5296 / 48,274704$

$\mathrm{n}=187,8$ eqüinos.

No momento da coleta dos soros dos animais foi aplicado um inquérito sócio-epidemiológico aos proprietários dos eqüinos (Anexo A), como forma de auxiliar no estudo dos manejos aos quais os animais estão envolvidos, assim como avaliar os meios de infecção dos eqüinos por Brucella e perpetuação da brucelose na região.

\section{RESULTADOS E DISCUSSÃO}

Do total de 187 soros sanguíneos analisados pelo teste do Antígeno Acidificado Tamponado (AAT) $100,0 \%$ se mostraram negativos.

Esses resultados encontrados são diferentes dos resultados de Feitosa et al. (1991) que verificaram $16,67 \%$ de positividade para eqüinos de áreas rurais. Por outro lado, Vianna et al. (1981) quando examinaram 810 soros de cavalos procedentes de diferentes regiões de Minas Gerais, obtiveram 0,37\% de positividade com títulos maiores que 1:100 pela prova de soroaglutinação rápida e 0,24\% quando utilizou o teste do cartão (AAT), ou seja, uma baixa prevalência, concordando com os resultados obtidos nesse trabalho.

Baruta et al. (2003), obtiveram 5,62\% de animais sorologicamente positivos quando analisaram 320 soros eqüinos da Província de La PampaArgentina, concordando com os valores revelados por MacMillan (1985), que obteve prevalência de brucelose entre 5,1\% e 9,9\% do total de 3.360 amostras de soros eqüinos. Já Stark et al. (2008) verificaram prevalência nula para 28 eqüinos de trabalho da cidade de Pelotas, concordando com os resultados obtidos nesse trabalho.

Resultado semelhante ao do presente trabalho foi revelado por Langoni et al. (1997) que examinaram 734 amostras de soro de eqüídeos e obtiveram apenas $6(0,82 \%)$ soros positivos, resultado pouco superior do encontrado por 
Nicolletti et al. (1982), que verificaram títulos maiores que 1:100 em 2,8\% dos 141 cavalos testados com antígenos de Brucella abortus pela prova de soroaglutinação em tubos.

Embora Tunala et al. (1994), afirmassem que animais portadores de abscessos de cernelha não deveriam ser relacionados com a brucelose, (diferentemente do resultado desta pesquisa), Silva et al. (2001) encontraram em eqüinos sintomáticos $73,1 \%$ de prevalência, este elevado valor se justificou pelo fato dos autores haverem estudado animais suspeitos e portadores de sintomatologia sugestiva da doença, igualmente Duff (1933) que isolou Brucella abortus entre $80,0 \%$ de 85 cavalos com fístula de cruz ou abscessos supurativos, diferentemente do presente trabalho, onde os animais não apresentavam sintomas clínicos sugestivos de brucelose.

Dos 187 soros eqüinos testados pelo AAT, 96 animais eram do sexo masculino, 79 do sexo feminino e em 12 animais não foi possível a identificação. Independentemente do sexo os animais se apresentaram soronegativos na pesquisa de anticorpos anti - Brucella abortus, através do Teste do Antígeno Acidificado Tamponado, como mostrado no quadro 1.

Quadro 1 - Pesquisa de anticorpos anti-Brucella abortus de acordo com o sexo, através do Teste do Antígeno Acidificado Tamponado, em eqüinos de trabalho de áreas rurais de Uberlândia - MG, 2009.

\begin{tabular}{lcccc}
\hline SEXO & $N^{\circ}$. EXAMINADOS & $\%$ & REAGENTES & $\%$ \\
\hline MACHO & 96 & 51,34 & $\mathrm{Z}$ & $\mathrm{Z}$ \\
FÊMEA & 79 & 42,24 & $\mathrm{Z}$ & $\mathrm{Z}$ \\
NÃO OBTIDO & 12 & 6,42 & $\mathrm{Z}$ & $\mathrm{Z}$ \\
TOTAL & 187 & 100 & $\mathrm{Z}$ & $\mathrm{Z}$ \\
\hline
\end{tabular}


Dos 96 machos examinados, 79 animais eram castrados e 17 não, tal fato é uma característica dos animais deste ecossistema, uma vez que o objetivo desses animais é o serviço de tração e não a reprodução.

O número alto de eqüinos castrados (79) e o fato da monta controlada ser o tipo de cobertura dos demais animais desta pesquisa poderiam estar contribuindo de forma significativa para os baixos índices desta doença, uma vez que Bishop et al. (1994) referiram que uma das principais vias de penetração das brucelas é através da mucosa genital, favorecida pelo coito.

Langoni \& Silva (1997), através de estudos sorológicos para diagnóstico da brucelose eqüina, não encontraram resultados significativos quando consideraram a idade, a raça e o sexo dos animais.

Os animais participantes deste estudo habitavam em ecossistema rural, sendo assim mantinham contato com diversas outras espécies, de menor valor na epidemiologia da doença, cuja maior importância zoosanitária prende-se aos bovinos. Rosemberg (1997) descreveu o ecossistema livre como aquele que animais infectados e o agente se encontram fora do ambiente, o que dificulta a manutenção das doenças nestes locais.

As espécies mais comuns que esses eqüinos conviviam eram bovinos, caninos, ovinos, caprinos, aves, suínos e outros eqüinos (Quadro 2).

A infecção de eqüídeos por brucelose seria favorecida pela coabitação destes com outras espécies de animais domésticos (LANGENEGGER \& SZECHY, 1961). Acha \& Szyfres (2001) revelaram que em nosso meio a principal fonte de contaminação de Brucella abortus aos eqüinos, é devido ao estreito contato desses com bovinos infectados.

Não houve queixa dos proprietários sobre sintomas clínicos sugestivos de brucelose, a alimentação era basicamente a pasto, eram alojados na maioria das vezes em baias coletivas, a maior parte dos sistemas de criação era extensiva e o tipo de cobertura era monta controlada. A principal doença relatada pelos proprietários foi garrotilho e houve um relato de botulismo.

Quanto ao manejo sanitário os animais normalmente eram casqueados e vermifugados, raramente as vacinações faziam parte do manejo, sendo 
utilizada vacina anti-rábica em algumas propriedades. As condições de manejo, o sistema de monta, alojamento e alimentação, contribuíram decisivamente como fatores limitantes para a disseminação desta doença a estes animais, tornando este um ecossistema ímpar, e livre da brucelose na espécie eqüina.

Quadro 2 - Espécies em contato com eqüinos de acordo com o resultado do teste do Antígeno Acidificada Tamponado (AAT), para o diagnóstico de brucelose eqüina na área rural de Uberlândia - MG, 2009.

\begin{tabular}{|c|c|c|c|c|}
\hline ESPÉCIES & EXAMINADOS & $\%$ & POSITIVOS & $\%$ \\
\hline Eqüinos & 06 & 3,20 & Z & Z \\
\hline Eqüinos + Bovinos & 25 & 13,36 & Z & Z \\
\hline Eqüinos + Aves + Suínos + Caninos & 9 & 4,81 & Z & Z \\
\hline $\begin{array}{l}\text { Eqüinos + Bovinos + Aves + } \\
\text { Caninos }\end{array}$ & 13 & 6,95 & Z & Z \\
\hline $\begin{array}{l}\text { Eqüinos + Bovinos + Aves + } \\
\text { Caninos + Suínos }\end{array}$ & 11 & 5,88 & Z & Z \\
\hline $\begin{array}{l}\text { Eqüinos + Bovinos + Ovinos + } \\
\text { Caprinos }\end{array}$ & 21 & 11,23 & Z & Z \\
\hline Eqüinos + Bovinos + Caninos & 19 & 10,16 & Z & Z \\
\hline $\begin{array}{l}\text { Eqüinos + Bovinos + Aves + Ovinos } \\
+ \text { Caninos }\end{array}$ & 19 & 10,16 & Z & Z \\
\hline $\begin{array}{l}\text { Eqüinos + Bovinos + Aves + Suínos } \\
\text { Eqüinos + Bovinos }+ \text { Aves }+\end{array}$ & 07 & 3,74 & Z & Z \\
\hline $\begin{array}{l}\text { Caninos + Suínos + Caprinos + } \\
\text { Ovinos }\end{array}$ & 30 & 16,04 & Z & Z \\
\hline Eqüinos + Bovinos + Aves + & & & & \\
\hline $\begin{array}{l}\text { Caninos + Felinos + Suínos + } \\
\text { Caprinos }\end{array}$ & 19 & 10,16 & Z & Z \\
\hline Bovinos + Aves & 01 & 0,53 & Z & Z \\
\hline Não soube informar & 07 & 3,74 & Z & Z \\
\hline TOTAL & 187 & 100 & Z & Z \\
\hline
\end{tabular}


SANTOS, A.L.Q. et al. Soroepidemiologia da Brucelose em equinos de trabalho de áreas rurais do Município de Uberlândia-MG. PUBVET, Londrina, V. 6, N. 12, Ed. 199, Art. 1336, 2012.

\section{CONCLUSÕES}

Nas condições em que foi realizada esta pesquisa:

- Todos os 187 eqüinos de trabalho de áreas rurais do município de Uberlândia-MG apresentaram sorologia negativa para brucelose.

- As propriedades investigadas revelaram ser um ecossistema livre da doença.

\section{REFERÊNCIAS}

ACHA, P. N.; SZYFReS, B. Brucellosis. Publ. Cient. Org. Panam. Salud, n. 503, p. 14-36, 1986.

ADAMS, L. G. The pathology of brucellosis reflects the outcome of the battle between the host genome and the Brucella genome. Vet. Microbiol. v. 90, p. 553-561, 2002.

BARUTA, D. A. et al. Diagnóstico serológico de brucelosis em eqüinos Del Departamento

Maracó. Província de La Pampa. Argentina. Veterinária Argentina, v. 20, n. 192, p. 117-121, 2003.

BATHKE, W. Brucellosis. In: BEER, J. (Ed.). Doenças infecciosas em animais domésticos: doenças causadas por vírus, clamídias, ricketticiose, micoplasmose. São Paulo: Roca, 1988. v. 2, p. 144-160.

BENNETT, J. C.; PLUM, F. Tratado de medicina interna. 20 ed. Rio de Janeiro: Guanabara Koogan, 1997. v. 2, 2647p.

BISHOP, G. C.; BOSMAN, P. P.; HERR, S. Bovine brucellosis. In: COETZER, J. A. N.; THOMSON, G. R.; TUSTIN, R. C. (Eds.). Infectious diseases of livestock. Austin: Texas A\&M University Press, College Station, 1994. v. 2, p. 1053-1066.

BLOOD, D. C.; RADOSTITS, O. M. Clínica Veterinária. 7 ed. Rio de Janeiro: Guanabara Koogan, 1991. p. 570-586.

BRASIL. Ministério da Agricultura e Abastecimento. Secretaria de Defesa Agropecuária. Departamento de Defesa Animal. Brucelose. Boletim de Defesa Animal, n. 27, p. 41-47, 1998.

BRASIL. Ministério da Agricultura, Pecuária e Abastecimento. Programa Nacional de Controle e Erradicação da Brucelose e da Tuberculose Animal (PNCEBT). Brasília :MAPA/SDA/DSA, 2005. 188p.

BUENO, M. A. et al. Estudo sorológico sobre a brucelose em eqüinos no estado de São Paulo e freqüência de aglutinações sensíveis ao 2-Mercaptoetanol e ao Ácido etileno diamino tetracético (EDTA). ARS Veterinária, Jaboticabal, SP, v. 18, n. 3, p. 280-286, 2002. 
CAMPANÃ, R. N.; GOTARDO, D. J.; ISHIZUCA, M. M. Epidemiologia e Profilaxia da Brucelose Bovina e Bubalina. Coordenadoria de Defesa Agropecuária CDA/SAA. Campinas, São Paulo. 2003. 20p.

CARRINGAN, M. J.; COCKRAM, F. A. Brucella abortus biotype 1 authritis in a horse. Aust Vet J, v. 64, n. 6, p. 190, 1987.

CARTER, G. R. \& CHEMGAPPA, M. M. Brucella. In: CARTER G. R. \& CHEMGAPPA, (Eds.)

Essentials of veterinary bacteriology and mycology. 4. ed. Philadelphia: London, 1991. p. 196-201.

CENTRO PANAmERICANO de ZOONOSES, Ramos Mejia. Procedimientos para estudos de prevalência por muestreo. Buenos Aires : CEPANZO, 1979. 39p (Nota Técnica 18).

DAVIS, J. W. et al. Brucelosis. In_. Enfermidades infecciosas de los mamiferos salvajes. Zaragoza (Espanha): Acribia, 1972. p. 302-309.

DENNY, H. R. A review of brucellosis in the horse. Equine Vet, v. 5, p. 121-125, 1973.

DIAS, H. L. T. Soroepidemiologia da Brucelose, Leptospirose, Anemia infecciosa equina, Herpesvirus equino tipo-1 e tipo-4 e Babesiose em equinos criados no Estado do Pará.. Belém. Tese (Doutorado em Ciências Biológicas). Universidade Federal do Pará, 2000.

DUFF, H. M. Brucella abortus in the horse. J. Comp. Path. p. 42-46, 1933.

FEITOSA, M. H. et al. Brucelose: levantamento sorológico no estado de São Paulo no período de 1977 a 1987. Veterinária e Zootecnia, São Paulo, SP, v. 3, p. 9-15, 1991.

GRASSO-PAULIN, L. M. S. O combate à brucelose bovina. São Paulo: 2000. $112 \mathrm{f}$.

Dissertação (Mestrado) - Faculdade de Medicina Veterinária e Zootecnia. Departamento de Medicina Veterinária Preventiva e Saúde Animal, Univ. de São Paulo, 2000.

JARDIM, E. C. et al. Presença de aglutininas anti-Brucella em eqüinos no Estado de Goiás. In: ENCONTRO, 8., 1979, Goiás. Anais...Goiás: Escola de Agronomia e Veterinária, UFGO, 1979. p. 150-155.

KOLODA, M. Cinética de produção de anticorpos em bezerras imunizadas com a cepa B19 de Brucella abortus (Frederick Bang, 1897). 2005. 69f. Tese (Mestrado em Ciências Veterinárias) - Setor de Ciências Agrárias, Universidade Federal do Paraná, Curitiba, 2005.

LANGENEGGER, J.; SZECHY, A. M. Brucelose dos eqüídeos domésticos - isolamento de Brucella abortus de bursites de cernelha no Brasil. Arq. Inst. Biol. Anim., v. 4, p. 49-63, 1961.

LANGONI, H.; VIEIRA, A. S. Comportamento sorológico de aglutininas anti-brucela em soro de eqüídeos. Revista Brasileira de Medicina Veterinária, v. 19, n. 2, p. 85-87, 1997.

LAUAR, N. M. Brucelose. Boletim técnico. CATI, São Paulo, n. 169, p. 13, 1983.

LOPES, C. F. A. et al. Avaliação soroepidemiológica da brucelose em animais e humanos procedentes da zona bragantina no estado do Pará - Brasil. Revista Brasileira de Reprodução Animal, v. 23, n. 3, p. 429-431, 1999.

LORD, V. R. et al. Soroprevalência de brucellosis em caballos de Venezuela. Veterinaria Tropical, v. 11, p. 31-41, 1986. 
MACMILLAN, A. P. et al. A retrospective study of de sorology of brucellosis in horses. Vet. Rec., v.177, p. 638-639, 1985.

MACMILLAN, A. P.; GREISSER-WILKE, I.; MOENINNIG, V.; MATHIAS, L. A. A competition enzyme immunoassay for brucellosis diagnosis. Dstch Tierärztl Wochenschr, v. 97, p. 83-85, 1990.

MACMILLAN, A. P.; STACK, J. Bovine Brucellosis. In OFFICE INTERNATIONAL DES EPIZOOTIES. Manual of Standards for Diagnostic Tests and Vaccines. 4 ed. Paris: Office International of Epizooties, p. 328-345, 2000.

MAURÍCIO, R.; COAST, P. A brucelose animal: revisão bibliográfica. Veterinária Técnica, Bragança, p. 46-53. abr. 1998.

MCCAUGHEY, W. J.; KERR, W. R. Abortion due Brucella in thoroughored mare. Vet. Rec., v. 80, p. 196-189, 1967.

MEGID, J.; Ribeiro, M. G.; MARCOS Jr., G.; GROCCI, A. J. Avaliação das provas de soroaglutinação rápida, soroaglutinação lenta, antígeno acidificado e 2-mercaptoetanol no diagnóstico da brucelose bovina. Brazilian Journal Veterinary Research Animal Science, São Paulo, v. 37. n. 5, 2000.

METCALF, H. E.; LUCHSINGER, D. W.; RAY, W. C. BRUCELLOSIS. In: BERAN, G. W.; STEELE, J. $H$. (Eds.). Handbook of zoonoses. section A: bacterial, rickettsial, chlamydial, and mycotic. 2.ed. Raton: CRC Press, 1994. p. 9-39.

MILK, M. E. Estudio serológico comparative entre equinos vacunados con Brucella abortus cepa 19 y un equino infectado naturalmente con Brucella abortus. Tese (Licenciatura) - Fac. Med. Vet. Zoot., U.N.A.M., México, 1974.

MOLNÁR, E.; MOLNÁR, L.; DIAS, H. L. T.; SOUZA, J. S.; VALE, W. G. Ocorrência de brucelose bovina no Estado do Pará confirmada por métodos sorológicos. Ver. Brás. Med. Vet., Rio de Janeiro, v. 22, n. 3, p. 117-121, 2000.

MORENO, E. Brucellosis in Central America. Vet. Microbiol, v. 90, n. 1, p. 31-38, 2002.

MORIYON, I. Estructura antigênica del gênero Brucella. Instituto Agronômico Mediterrâneo de Zaragoza, p. 39-53, 1988.

NICOLETTI, P. L. The epidemiology of bovine brucellosis. Adv. Vet. Sci. Comp. Med., v. 24, p. 69-95, 1980.

NICOLETTI, P. L. et al. Study of aglutinins to Brucella abortus, B. canis and Actinobacillus equuli in horses. Equine Veterinary Journal, v. 14, p. 302-302, 1982.

NICOLETTI, P. L. et al. Brucelose nos grandes animais. Manual Merck de Veterinária. ROCA. $8^{a}$ ed. p. 823-826, 2001.

OMS - ORGANIZACION MUNDIAL DE LA SALUD, Comité Mixto FAO/OMS de Expertos en Brucelosis. Informe técnico n. 740. Genebra, 1986. p. 146.

POESTER, F. P. Vacinas Contra a Brucelose Bovina: Situação Atual e Perspectivas. Centro de Pesquisa Veterinária "Desidério Finamor". Arquivo do Instituto Biológico de São Paulo, v. 60, n. 2 jul/dez. 1998. p. 37. 
RADOSTITS, O. M. et al. A textbook of the diseases of cattle, sheep, pigs, goats and horses. Veterinary medicine. 9. ed. London: W. B. Saunders, 2000. p. 867-891.

ROJO, L. J. Estudio serológico sobre brucelosis em eqüinos de México. Tese (Licenciatura) - Fac. Med. Vet. Zoot., U.N.A.M., México, 1973.

ROSEMBerg, F. J. Princípios de epidemiologia. Rio de Janeiro : CPZ, 1977. 89p. Apostila. SHORTRIDGE, E. H. Two cases of suspected Brucella abortus abortium in mares. N. Z. Vet. J. (N.Z.), v. 15 p. 33-34, 1967

SIEGMUND, O. H.; FRASER, C. M. El Manual Merck De Veterinária. Rahway (USA), Ed. Merck \& Co, Inc,1981. 1386p.

SILVA, L. A. F. et al. Soroprevalência de brucelose em eqüínos com bursite cervical ou nucal. Arquivo de Ciências Veterinária e Zoologia, v. 4, n. 1, p. 19-23, 2001.

STARK, C. B.; AMARAL, L. A.; HENTGES, A.; JORGE, S.; MARTINS, P. L.; BANDEIRA, F. S.; FERNANDES, C. P. H.; NOGUEIRA, C. E. W.; BROD, C. S.; RECUERO, A. L. C. Pesquisa de anticorpos anti-brucela em animais de tração atendidos no hospital veterinário da Universidade Federal de Pelotas. In: CONGRESSO BRASILEIRO DE MEDICINA VETERINÁRIA, 35., 2008, GRAMADO, RS. Anais..... (online), Gramado: Conbravet, 2008. Disponível:

http://www.sovergs.com.br/conbravet2008/anais/cd/resumos/R1348-1.pdf. Acesso em 13 jul. 2009.

TEIXEIRA, A. C. P.; SOUZA, C. F. A.; SÁ, M. J. S.; RIBEIRO, R. M. P.; OLIVEIRA, A. L.; SOUZA, R. M. Brucelose - zoonose controlada? Higiene Alimentar, v. 12, n. 54, p. 23-25, 1998.

TIMONEY, J. F.; GILLESPIE, J. H.; SCOTT, F. W.; BARLOUGH, J. E. Hagan and Bruner's microbiology and infectious diseases of domestic animals. London: Comstock Publishing Associates. Division of Cornell University Press, 1988. p. 135-144.

TUNALA, V.; LACERDA NETO, J. C.; MATHIAS, L. A. Pesquisa de anticorpos contra Brucella em soros de eqüinos com e sem abscesso de cernelha. Ars. Vet, v. 10, n. 2, p. 216, 1994.

VASCONCELLOS, S. A.; ITO, F. H.; CÔRTES, J. A. Bases para a prevenção da brucelose animal. Comun. Cient. Fac. Med. Zootec. USP, v. 1, p. 25-36. 1987.

VIANNA, F. C. et al. Inquérito sorológico para brucelose equina em Minas Gerais. Arq. Esc. Vet. UFMG, v. 33, p. 431-435, 1981.

YOUNG, E. H. An overview of human brucellosis. Clinical Infectious Diseases, v. 21, p. 283290, 1995. 


\section{ANEXO A - Inquérito sócio-epidemiológico:}

\section{INFORMAÇÕES REFERENTES AO PROPRIETÁRIO E A PROPRIEDADE}

Nome do proprietário:

Endereço:

CEP:

Telefone:

Grau de escolaridade do proprietário: Completo Incompleto

\begin{tabular}{|c|c|c|}
\hline Primário & ( ) & ( ) \\
\hline $1^{\circ} \mathrm{Grau}$ & ( ) & ( ) \\
\hline $2^{\circ} \mathrm{Grau}$ & ( ) & ( ) \\
\hline Nível Superior & ( ) & ( ) \\
\hline
\end{tabular}

Nome da Propriedade:

Município:

Mora na propriedade:

Área da propriedade:

Exploração principal da propriedade:

Tipo de mão de obra:

2. INFORMAÇÕES REFERENTES AO PLANTEL DE EQÜINOS 
$N^{\circ}$ total de animais (Distribuição por sexo e idade):

Raça predominante:

Sistema de criação:

Intensivo ( ) Semi-extensivo ( ) Extensivo ( )

Exploração principal:

Tipo de Instalação:

Galpão ( ) Baia Individual ( ) Baia Coletiva ( )

Não tem ( )

Tipo de pastagem:

Alimentação:

Lotes Vagos ( ) Pasto ( ) Volumoso ( ) Concentrado ( )

Outros ( )

Tipo de cobertura:

Monta a campo ( ) Monta controlada ( ) Inseminação artificial ( ) Sem controle ( )

Repetição de cio: $\quad$ Não ( ) $\quad \operatorname{Sim}($ )

Freqüência:

Sinais Clínicos sugestivos de Brucelose:

Hiporexia

Emagrecimento

Febre

$\begin{array}{ll}\text { Não ( ) } & \operatorname{Sim}(\text { ) } \\ \text { Não ( ) } & \operatorname{Sim}(\text { ) } \\ \text { Não ( ) } & \operatorname{Sim}(\text { ) }\end{array}$




$\begin{array}{lll}\text { Abscesso de cernelha } & \text { Não ( ) } & \operatorname{Sim}(\text { ) } \\ \text { Abortos } & \text { Não ( ) } & \operatorname{Sim}(\text { ) } \\ \underline{\text { Infertilidade }} & \text { Não ( ) } & \operatorname{Sim}(\text { ) }\end{array}$

Mortalidade média no ano, idade e sexo dos mortos:

Realiza algum tipo de manejo sanitário nos animais? Qual (is)?

Os animais são vacinados contra alguma doença? Qual (is)?

Tem alguma doença diagnosticada na propriedade?

Qual é a fonte de água em sua propriedade?

\section{INFORMAÇÕES REFERENTES A OUTROS ANIMAIS DA PROPRIEDADE}

Há outras espécies animais na propriedade? Qual (is)?

Presença de animais sinantrópicos:

Principais doenças diagnosticadas nas outras espécies: 